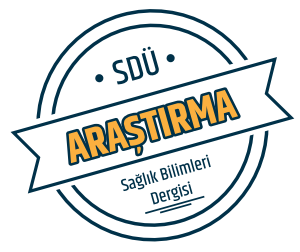

Sdü Sağlık Bilimleri Dergisi / Cilt 10 Sayı 2 / 2019

\title{
Resiprokal ve Rotasyonel Hareket ile Çalışan Yeni Nesil Tek Eğe Sistemlerinin Şekillendirebilme Etkinliklerinin Konik Işınlı Bilgisayarlı Tomografi Kullanarak Karşılaştırılması \\ Comparison of the Shaping Efficiency of New Generation Single File Systems Using Reciprocal and Rotational Motion Using Cone Beam Computed Tomography
}

\author{
Ayşe Aydoğmuş Erik ${ }^{1}$, Cevat Emre Erik², Derya Yıldırım ${ }^{1}$ \\ ${ }^{1}$ Süleyman Demirel Üniversitesi, Diş Hekimliği Fakültesi, Ağız, Diş ve Çene Radyolojisi Anabilim Dalı, Isparta, Türkiye. \\ ${ }^{2}$ Süleyman Demirel Üniversitesi, Diş Hekimliği Fakültesi, Endodonti Anabilim Dalı, Isparta, Türkiye.
}

\section{Özet}

Amaç: Farklı üretim şekli ve farklı çalışma prensibine sahip yeni nesil tek eğe sistemlerinin oval kanallar üzerindeki şekillendirme özelliklerinin konik ışınlı bilgisayarlı tomografi görüntülerinde (KIBT) doğrusal ölçüm yöntemi kullanılarak karşılaştırılmasıdır.

Materyal-Metot: $\mathrm{Bu}$ çalışma için, kalsifiye olmayan, oval tek kanala sahip on beş mandibular kesici diş seçildi. Dişler rastgele 3 gruba ayrıldı $(n=5)$. Kanal preperasyonları One Curve (Micro-Mega, Besançon, Fransa), Hyflex EDM (Coltene-Whaledent,Altstatten, İsviçre), WaveOne GOLD (Dentsply Sirona Endodontics, Ballaigues, İsviçre) eğe sistemleri kullanarak üretici talimatlarına uygun olarak tamamlandı. Preperasyon öncesi ve sonrası dişlerden konik 1şınlı bilgisayarlı tomografi alındı. Transportasyon ve merkezleyebilme oranları apikalden 3, 6 ve 9mm uzaklıkta hesapland1. Elde edilen veriler ANOVA, Tukey ve t-test kullanılarak değerlendirildi.

Bulgular: Kanal transportasyon oranı değerlendirildiğinde eğeler arasında $3 \mathrm{~mm}$ seviyesinde bukkal-lingual düzlemde grup 1 (One Curve) en düşük transportasyon oranına sahipken, grup 2 (Hyflex EDM) en yüksek transportasyon oranına sahip olduğu gözlendi $(p<0,05)$. Merkezleyebilme oranları açısından tüm düzlem ve seviyelerde gruplar arasında anlamlı farklılık gözlenmedi ( $\mathrm{p}>0,05)$.

Sonuç: Bu çalışmanın sınırları dahilinde rotasyonel hareket yapan eğeler ile resiprokal hareket yapan eğe arasında tranportasyon oranı ve merkezleyebilme oranı arasında bir fark bulunmamaktadır.

Anahtar kelimeler: Hyflex EDM, One Curve, WaveOne GOLD, Transportasyon, Merkezleyebilme.

\section{Giriş}

Kök kanallarının şekillendirilmesi endodontik tedavide kök kanal dezenfeksiyonunu ve kök kanal dolumunu etkileyen önemli bir unsurdur (1). Kök kanallarının şekillendirilmesinde kullanılan ideal enstrümentasyon tekniği ile kök kanalın çevreleyen periferal sağlam dentin korunurken; kanalın

\begin{abstract}
Objective: To compare the shaping ability of new generation single-file systems on different oval canals with different production methods and different working principles by using linear measurement method in cone beam computed tomography images (CBCT).

Material-Method: Fifteen mandibular first incisor uncalcified oval canals were selected. The teeth were randomly divided into 3 groups $(n=5)$. Canal preperation with the One Curve (Micro-Mega, Besançon, France), Hyflex EDM (ColteneWhaledent,Altstatten, Switzerland) and WaveOne GOLD (Dentsply Sirona Endodontics, Ballaigues, Switzerland) systems was performed according to the manufacturers instructions. Cone-beam computed tomographic images were taken before and after instrumentation. Transportation and centering ability was calculated in the distances of 3,6 , and $9 \mathrm{~mm}$ from the apex. ANOVA, Tukey and t-test were used to statistically analyze the data.
\end{abstract}

Results: When the canal transport ratio was evaluated, group 1 (One Curve) had the lowest transport ratio in the buccal-lingual plane at $3 \mathrm{~mm}$, while group 2 (Hyflex) had the highest transport ratio $(\mathrm{p}<0.05)$. No significant differences was observed between the groups at all levels and planes in terms of centering ability ( $>00.05)$.

Conclusions: Within the limits of this study, there is no differences in tranportation ratio and centering ability between the file systems that rotation motion and reciprocal motion systems.

Keywords: Hyflex, One Curve, WaveOne GOLD, Transportation, Centering Ability .

tüm yüzeylerine temas ederek, kök kanalını dolum için tam olarak hazırlamalıdır. Ancak kök kanal anatomisindeki farklılıklar sebebiyle debrislerin kök kanallarından tamamen uzaklaştırılması çok zordur (2).

Nikel-Titanyum (Ni-Ti) döner aletler üzerine yapılan son araştırmalarda orijinal kanal formunu değiştirmeden,

Yazışma Adresi / Corresponding: Ayșe Aydoğmuş Erik,

Süleyman Demirel Üniversitesi, Dis Hekimliği Fakültesi,

Ağız, Diş ve Çene Radyolojisi Anabilim Dalı, Isparta, Türkiye.

Tel: 05058242570

E-posta / E-mail: dt.ayseaydogmus@gmail.com 
iatrojenik hataların en aza inmesini sağlayan yeni tasarımlar dikkat çekmektedir (3). Ayrıca son yıllarda uygulayıcının verimliliğini arttırmak, tedavi için gerekli süreyi kısaltmak amacıyla birçok üretici farklı hareketlerde çalışan tek eğe sistemleri geliştirmişlerdir.

One Curve eğe sistemleri 1sıl işlem görmüş Ni-Ti alaşımından üretilen devamlı rotasyon hareketi ile çalışan tek eğe sistemlerindendir. Yüksek esneklik kabiliyeti ve kırılma direncine sahiptir. Üretimi esnasında kullanılan C-wire teknolojisi sayesinde erișimi zor olan ve mikrobiyal eliminasyonu zor olan kanallarda bile ön eğim verilerek kullanılabilme olanağı sağlar (4).

Hyflex EDM CM-wire'ın elektriksel deşarj işlemine maruz kalması sonucu elde edilen devamlı rotasyon hareketi ile çalışan eğelerdir. Üretiminde kullanılan teknoloji sayesinde üstün kırılma direnci ve kesme etkinliğine sahiptir. Eğenin apikal çap1 0,25mm'dir ve şaft boyunca değişen çaplara sahiptir. Bu eğe üç farklı bölgede üç farklı kesite sahiptir (apikal bölgede 'quadratic', orta bölgede 'trapezoidal', koronal bölgede 'triangular') (5).

WaveOne GOLD eğe sistemleri resiprokal hareket ile çalışan tek eğe sistemleridir. Eğeye üretimi esnasında 1sıl işlem uygulanmış ve yarı martensit fazda kalması sağlanmıştır. $\mathrm{Bu}$ eğenin çapraz kesitinde, merkezi bölge dışındaki bölgelerde iki kesici kenara sahiptir ve bu yapıya 'paralelogram' adı verilir (6).

Kök kanal eğe sistemlerinin şekillendirme yeteneklerinin değerlendirilmesinde günümüzde histolojik inceleme, seri kesit alınması, taramalı elektron mikroskop kullanılması, radyografik karşılaştırmalar, enstrümante edilen dişlerin silikon ile modellenmesi, mikro bilgisayarlı tomografi gibi çeşitli yöntemler kullanılmıştır. Ayrıca konik 1şınlı bilgisayarlı tomografide (KIBT) yapilan incelemeler de günümüzde şekillendirme yeteneklerinin değerlendirilmesi için kullanılan yöntemlerdendir. Bu yöntemin en önemli avantajı işlem öncesi ve sonrasında dişin kesilmesine gerek kalmamasıdır (1, 7-9). KIBT ile elde edilmiş üç boyutlu görüntülerin kalitesi diğer tüm yöntemlerden daha üstündür $(7,8,10)$. KIBT görüntülerinin çözünürlügüünün yüksek olması detayın ölçülebildiği doğruluğu belirlediğinden, analizlerin etkinliğini artırır. KIBT görüntülerinde doğrusal ölçümlerin doğruluğu üzerine yapılan birçok araştırmada, doğrusal ölçüm yönteminin güvenilir ve uygulanabilir bir yöntem olduğu belirtilmiştir (11-13).

Literatür incelemeleri neticesinde çalışmamızda kullandığımız One Curve (Micro-Mega, Besançon, Fransa), Hyflex EDM (Coltene-Whaledent,Altstatten, İsviçre) ve WaveOne GOLD (Dentsply Sirona Endodontics, Ballaigues, İsviçre) eğelerinin şekillendirme etkinliklerinin KIBT kullanılarak değerlendirildiği bir çalıșmaya rastlanmamıștır. Bu çalışmada amacımız, farklı üretim teknikleri ve farklı çalışma prensibine sahip yeni nesil tek eğe sistemlerinin oval kanallar üzerindeki şekillendirme kabiliyetlerinin KIBT görüntülerinde doğrusal ölçüm yöntemi kullanılarak karşılaștırılmasıdır.

\section{Materyal-Metot}

Örnek sayısının belirlenebilmesi için, planlanan üç gruptan her bir grupta üç adet olmak üzere toplam dokuz örneğin deneyleri tamamlanıp ölçümleri yapıldı. Ön çalışma sonrasında eğe sistemlerinin grup ortalama farklarının sırasıyla 2,43; 1,$61 ; 0,66$ ve ön çalışma sonrası tahmin edilen popülasyon standart sapmalarının 0,5744 kabul edildiğinde \%95 güç ile her bir grupta olması gereken örnek sayısının en az beş olması gerektiği sonucuna ulaşılmıştır.

Çalışma Protokolü Süleyman Demirel Üniversitesi Girişimsel Olmayan İnsan Etik Kurulu tarafından onaylandı (13.12.2018/200). Çalışmada kullanılmak üzere oval tek kanala sahip çürük, çatlak, kırık bulunmayan, apeks gelişimi tamamlanmış, benzer kök uzunluğuna ve morfolojiye sahip, periodontal sebeplerle çekilmiş 15 mandibular kesici diş rastgele örnekleme yoluyla seçildi.

Dişlerin kronları mine-sement bileşiminden $3 \pm 1 \mathrm{~mm}$ koronalden olacak şekilde uzaklaştırıldı. Dişlerin çalışma boyları 10 numaralı K file kullanılarak stereomikroskop (Leica S4E, Leica microsystems GmbH, Wetzlar, Almanya) altında eğenin ucu apikalde görülene kadar ilerletilip belirlenmiştir. Çalışma boyları belirlenen dişler preperasyon sırasında kullanılacak Ni-Ti rotary enstrümanlara göre üç gruba $(n=5)$ ayrild1 (One Curve, Hyflex EDM, WaveOne GOLD).

Kök kanal preperasyonları tek bir operatör tarafından üretici firmanın talimatları doğrultusunda yapıldı.

Grup 1: One Curve $(25 / 0,06)$ eğe grubunda olan örnekler üretici firmanın talimatları doğrultusunda 300rpm hızda $2,5 \mathrm{Ncm}$ tork altında 'devamlı rotasyonel hareket' ile genişletildi $(n=5)$.

Grup 2: Hyflex EDM (25/ ) eğe grubunda bulunan örnekler üretici firmanın talimatları doğrultusunda 500rpm hızda $2,5 \mathrm{Ncm}$ tork altında 'devamlı rotasyonel hareket' ile genişletildi $(n=5)$.

Grup 3: WaveOne Gold $(25 / 0,07)$ eğe grubunda bulunan örnekler 'Wave One ALL' resiprokasyon programı kullanılarak yumuşak parmak baskısı ve firçalama hareketleri yaparak üretici firmanın talimatları doğrultusunda genişletildi $(\mathrm{n}=5)$.

Eğe sistemleri uygulanmadan önce tüm dişler 15 numaralı ' $\mathrm{k}$ ' eğesi apikalde sıkışıncaya kadar genişletilmiştir. Bütün kök kanallarında enstrümentasyon boyunca ve final irrigasyonu olarak toplam $10 \mathrm{ml} \% 2,5 \mathrm{NaOCI}$ kullanıldı. Her bir enstrüman tek bir kök kanalında kullanıldı.

KIBT görüntü edinmesi ve değerlendirilmesi; dişler silikon ölçü maddesi içerisine tek tek yerleştirildi ve her bir diş kök örneği için preperasyon öncesi ve sonrası olmak üzere 2 defa KIBT (Planmeca ProMax 3D Mid, Helsinki, Finland) taraması yapıldı. Görüntülemede flat panel dedektör sistemi olan KIBT cihazı ile $90 \mathrm{kVp}, 14 \mathrm{~mA}, 15,1 \mathrm{sn}$, çözünürlük ayarları $0.15 \mathrm{~mm} 3$ voksel boyutunda, 40X50mm görüntü alanında (Field of view, FOV) tarama gerçekleştirildi. Görüntüler Romexis yazılımında (Planmeca Oy, Helsinki, Finland) incelendi. Tüm örneklerin KIBT görüntülerinde koronal, sagittal ve aksiyel kesitlerde rehber düzlemler kök 
kanalının tam ortasından geçecek şekilde çakıştırıldı ve aksiyel kesitlerde ölçümler gerçekleştirildi. KIBT görüntüleri üzerinde her bir dişin kökünün üç seviyesinde $(3,6,9 \mathrm{~mm})$ ve dört ayrı yönde (bukkal, lingual, mesial ve distal) dentin kalınlığının doğrusal olarak ölçümleri yapıldı (Şekil 1). Her bir doğrusal ölçüm diş kökünün kanal duvarı ile dentin dış çeperi arasında gerçekleştirildi. Her bir seviyede farklı yönlerde (bukkal, lingual, mesial ve distal) belirlenen dentin kalınlığı preperasyon öncesi ve sonrası olarak kaydedildi. Toplamda 360 doğrusal ölçüm gerçekleştirildi. Ölçümlerin \%20'si 2 hafta sonra tekrar edildi. Alınan KIBT görüntüleri loş bir odada 15.6“ TOSHIBA SEC 3150 PnP monitörde (TOSHIBA EUROPE GMBH, Hammfelddamm, Germany), 1366 X768 piksel ekran çözünürlüğünde, 64 bit renk derinliğinde değerlendirildi.

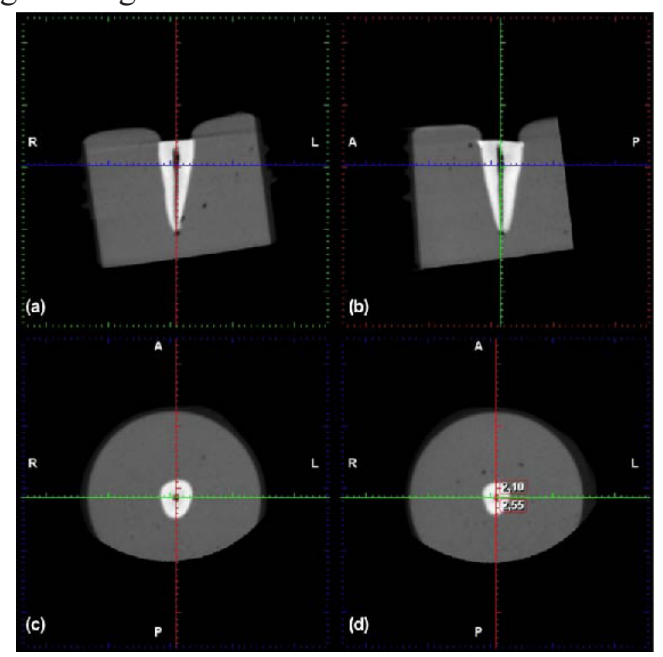

Şekil 1. Diş kök örneğinin (a) koronal kesit, (b) sagittal kesit, (c) aksiyel kesit, (d) aksiyel kesitte dentin kalınlığının doğrusal ölçümünün yapıldığı KIBT görüntüleri

Kullanılan eğe sistemlerinin neden olduğu kök kanal formu transportasyon miktarları ve merkezleyebilme oranları aşağıdaki formüller kullanılarak 3 farklı seviyede (3, 6 ve $9 \mathrm{~mm}$ ) değerlendirilmiştir (Şekil 2).

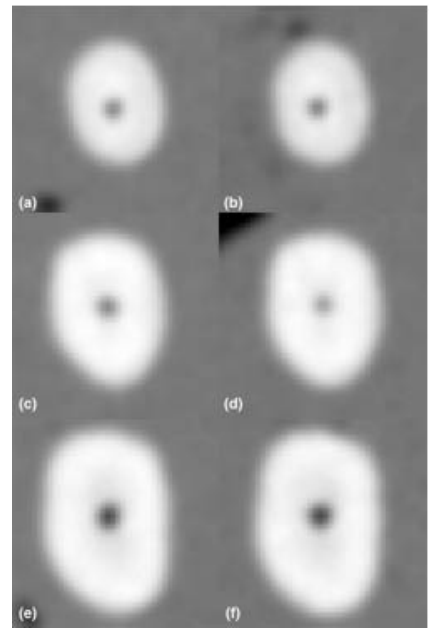

Şekil 2. One Curve eğe sistemi ile kök kanal preparasyonunun yapıldığ 1 diș kök örneğinin enstrümante edilmeden önce (a) $3 \mathrm{~mm}$, (c) $6 \mathrm{~mm}$, (e) $9 \mathrm{~mm}$ seviyesinde; enstrümantasyon sonras1 (b) $3 \mathrm{~mm}$, (d) $6 \mathrm{~mm}$, (f) $9 \mathrm{~mm}$ seviyesinde aksiyel kesitte KIBT görüntüsü
Her bir seviyede transportasyon miktarının belirlenmesi için aşağıdaki formül kullanıldı:

$$
(\mathrm{m} 1-\mathrm{m} 2)-(\mathrm{d} 1-\mathrm{d} 2)
$$

$\mathrm{Bu}$ formülde $\mathrm{ml}$ kanal enstrümantasyonundan önce kanalın kökün mesial kenarına olan mesafesi, m2 kanal enstrümantasyonundan sonra kanalın kökün mesial kenarına olan mesafesi, d1 kanal enstrümantasyonundan önce kanalın kökün distal kenarına olan mesafesi, d2 kanal enstrümantasyonundan sonra kanalın kökün distal kenarına olan mesafesidir.

$$
(\mathrm{b} 1-\mathrm{b} 2)-(11-12)
$$

$\mathrm{Bu}$ formülde $\mathrm{b} 1$ kanal enstrümantasyonundan önce kanalın kökün bukkal kenarına olan mesafesi, b2 kanal enstrümantasyonundan sonra kanalın kökün bukkal kenarına olan mesafesi, 11 kanal enstrümantasyonundan önce kanalın kökün lingual kenarına olan mesafesi, 12 kanal enstrümantasyonundan sonra kanalın kökün distal kenarına olan mesafesidir.

$\mathrm{Bu}$ formüle göre, ' 0 ' değeri kanal transportasyonunun olmaması, mesial, distal, bukkal veya lingual düzlemlere göre pozitif ve negatif değerler kanal tranportasyonunu ifade etmektedir.

Her bir seviyedeki merkezleme oranının belirlenmesi için aşağıdaki formül kullanıldı:

$$
\begin{gathered}
(\mathrm{m} 1-\mathrm{m} 2) /(\mathrm{d} 1-\mathrm{d} 2) \text { veya }(\mathrm{d} 1-\mathrm{d} 2) /(\mathrm{m} 1-\mathrm{m} 2) \\
(\mathrm{b} 1-\mathrm{b} 2) /(11-12) \text { veya } \quad(11-12) /(\mathrm{b} 1-\mathrm{b} 2)
\end{gathered}
$$

Bu formüle göre, ' 1 ' değeri kök kanalının tamamen merkeze bağlı kaldığını, diğer değerler ise kök kanal doğrultusunun değiştiğini göstermektedir.

Toplanan verilerin istatistiksel analizleri SPSS (version 23.0; IBM Corp., Armonk, NY, USA) kullanılarak yapıldı. Gözlemci içi uyumu değerlendirmek için sınıf içi korelasyon katsayısı (Interclass correlation coefficient, ICC) kökün 3 seviyesi için hesaplandı. Gruplar arası (farklı eğe sistemleri) farklı seviyelerdeki kök kanalının transportasyon oranları ve merkezleyebilme oranlarının karşılaştırılmasında One-Way ANOVA ve Tukey testi kullanıldı. Grup içi kök kanalının transportasyon oranı ve merkezleyebilme oranlarının bölgesel olarak farklılıklarının değerlendirilmesinde t-testi kullanıldı. İstatistiksel önem düzeyi $\% 5$ olarak belirlendi.

\section{Bulgular}

Kökkanalı preparasyonöncesive sonrasının değerlendirmesinde yapılan doğrusal ölçümler karşılaştırıldığında sınıf içi korelasyon katsayısının gözlemci içi uyum için mükemmel düzeyde olduğu belirlendi (ICC=0,965-0,995).

$\mathrm{Bu}$ çalışmada, Tablo 1 gruplar arasında farklı seviyelerdeki kök kanalının transportasyon oranlarının ortalama ve standart sapma değerlerini göstermektedir. 
Tablo 1. One Way ANOVA ve Tukey test sonuçları

\begin{tabular}{lcccccc}
\hline \multirow{2}{*}{ Gruplar } & \multicolumn{3}{c}{ Mesio-distal düzlem Ort \pm SS } & \multicolumn{3}{c}{ Bukkal-lingual düzlem Ort \pm SS } \\
\cline { 2 - 7 } & $\mathbf{3 m m}$ & $\mathbf{6 m m}$ & $\mathbf{9 m m}$ & $\mathbf{3 m m}$ & $\mathbf{6 m m}$ & $\mathbf{9 m m}$ \\
\hline Grup 1 (One curve) & $0,056 \pm 0,03$ & $0,058 \pm 0,03$ & $0,12 \pm 0,02$ & $0,090 \pm 0,03^{\mathrm{B}}$ & $0,11 \pm 0,05$ & $0,16 \pm 0,04$ \\
Grup 2 (Hyflex) & $0,004 \pm 0,002$ & $0,12 \pm 0,05$ & $0,09 \pm 0,03$ & $0,26 \pm 0,06^{\mathrm{A}}$ & $0,03 \pm 0,02$ & $0,14 \pm 0,06$ \\
Grup 3 (WaveOne GOLD) & $0,052 \pm 0,03$ & $0,086 \pm 0,03$ & $0,04 \pm 0,02$ & $0,092 \pm 0,03^{\mathrm{AB}}$ & $0,06 \pm 0,03$ & $0,21 \pm 0,03$ \\
\multicolumn{1}{c}{$\mathbf{P}$} & 0,34 & 0,59 & 0,18 & $\mathbf{0 , 0 3}$ & 0,42 & 0,61 \\
\hline
\end{tabular}

Kök kanallarının apikalden 3, 6 ve 9 mm uzaklıktaki mesio-distal ve bukkal-lingual düzlemdeki transportasyon miktarlarının ortalama (Ort) ve standart sapmalarını(SS) göstermektedir.

*Sütun içerisinde üst simge olarak gösterilen harfler gruplar arasındaki anlamlı farklılıkları göstermektedir $(\mathrm{p}<0,05)$.

Gruplar arası transportasyon oranlarının ve merkezleyebilme oranlarının değerlendirildiği Tukey test sonuçlarına göre transportasyon oranları için gruplar arası istatistiksel olarak farklı tek sonuç B-L düzlemde $3 \mathrm{~mm}$ seviyesinde gözlenmektedir. B-L düzlemde $3 \mathrm{~mm}$ de, grup 2 istatistiksel olarak en yüksek transportasyon oranına sahipken, grup 1'in en düşük transportasyon oranına sahip olduğu sonucuna ulaşılmıştır $(p<0,05)$ (Tablo 3). Merkezleyebilme oranlarına göre gruplar arasında anlamlı fark bulunmadı $(\mathrm{p}>0,05)($ Şekil 3). Gruplar arasında diğer seviyelerde ve düzlemlerde istatistiksel olarak farklılık bulunmadı $(\mathrm{p}>0,05)$ (Tablo 1).

Grup içi tranportasyon oranlarının bölgelere göre farklarının değerledirildiği t-test sonuçlarına göre istatistiksel olarak grup içi bölgesel farklılık grup 2 ve grup 3 gözlenmiştir. Grup 2 (Hyflex EDM) de $3 \mathrm{~mm}$ seviyesinde B-L düzlemde M-D gözleme göre anlamlı olarak yüksek oranda transportasyon gözlenmiştir $(\mathrm{p}<0,05)$. Grup 3 (WaveOne GOLD) da 9mm seviyesinde B-L düzlemde M-D düzleme göre anlamlı olarak yüksek oranda transportasyon gözlenmiştir $(\mathrm{p}<0,05)$. Diğer tüm seviyelerde anlamlı farklılık bulunmamıştır $(\mathrm{p}>0,05)$ (Tablo 2).

Tablo 2. Grup içi karşılaştırma için kullanılan t-test sonuçları

\begin{tabular}{|c|c|c|c|c|}
\hline Gruplar & Seviyeler & Bölgeler & Ort \pm SS & $\mathbf{P}$ \\
\hline \multirow{6}{*}{$\begin{array}{l}\text { Grup } \\
1 \text { (One } \\
\text { Curve) }\end{array}$} & \multirow{2}{*}{$3 \mathrm{~mm}$} & b-1 & $0,09 \pm 0,03$ & \multirow{2}{*}{0,507} \\
\hline & & m-d & $0,06 \pm 0,03$ & \\
\hline & \multirow{2}{*}{$6 \mathrm{~mm}$} & $b-1$ & $0,11 \pm 0,05$ & \multirow{2}{*}{0,449} \\
\hline & & $\mathrm{m}-\mathrm{d}$ & $0,06 \pm 0,04$ & \\
\hline & \multirow{2}{*}{$9 \mathrm{~mm}$} & b-1 & $0,16 \pm 0,05$ & \multirow{2}{*}{0,467} \\
\hline & & m-d & $0,12 \pm 0,02$ & \\
\hline \multirow{6}{*}{$\begin{array}{c}\text { Grup } 2 \\
\text { (Hyflex) }\end{array}$} & \multirow{2}{*}{$3 \mathrm{~mm}$} & $b-1$ & $0,26 \pm 0,06^{\mathrm{A}}$ & \multirow{2}{*}{0,003} \\
\hline & & $m-d$ & $0,004 \pm 0,002^{\mathrm{B}}$ & \\
\hline & \multirow{2}{*}{$6 \mathrm{~mm}$} & b-1 & $0,03 \pm 0,02$ & \multirow{2}{*}{0,188} \\
\hline & & $m-d$ & $0,12 \pm 0,06$ & \\
\hline & \multirow{2}{*}{$9 \mathrm{~mm}$} & $b-1$ & $0,14 \pm 0,06$ & \multirow{2}{*}{0,578} \\
\hline & & m-d & $0,10 \pm 0,03$ & \\
\hline \multirow{6}{*}{$\begin{array}{c}\text { Grup } 3 \\
\text { (WaveOne } \\
\text { GOLD) }\end{array}$} & \multirow{2}{*}{$3 \mathrm{~mm}$} & $b-1$ & $0,09 \pm 0,03$ & \multirow{2}{*}{0,420} \\
\hline & & $m-d$ & $0,05 \pm 0,03$ & \\
\hline & \multirow{2}{*}{$6 \mathrm{~mm}$} & $b-1$ & $0,06 \pm 0,03$ & \multirow{2}{*}{0,646} \\
\hline & & $\mathrm{m}-\mathrm{d}$ & $0,09 \pm 0,03$ & \\
\hline & \multirow{2}{*}{$9 \mathrm{~mm}$} & $b-1$ & $0,21 \pm 0,04^{¥}$ & \multirow{2}{*}{0,005} \\
\hline & & $m-d$ & $0,05 \pm 0,02^{\ltimes}$ & \\
\hline
\end{tabular}

Gruplarn her bir seviyedeki transpottasyon miktarlarnın bölgesel (OrtıSS) olarak karșlașturlmasııı vermektedir *Sütun içinde üst simge ile gösterilen farklı karakterler bölgeler arası farkllı̆ı̆ göstermektedir $(\mathrm{p}<0,05)$.

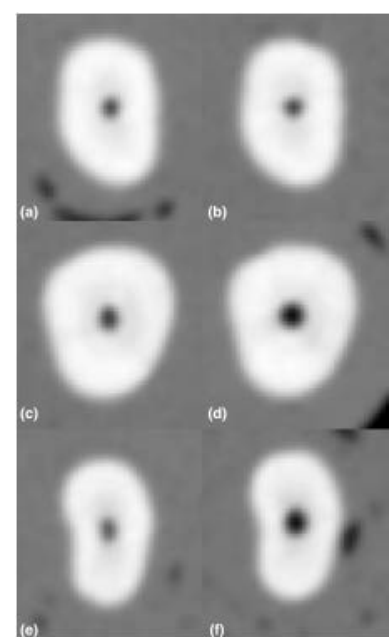

Sekil 3. Kök kanal praparasyonunun yapıldığ $9 \mathrm{~mm}$ seviyesinde KIBT aksiyel kesit örnekleri: enstrümante edilmeden önce (a) One Curve (c) Hyflex EDM, (e) WaveOne GOLD; enstrümantasyon sonras1 (b) One Curve, (d) Hyflex EDM, (f) WaveOne GOLD eğe sistemleri

Tablo 3. Grup içi karşılaştırma için kullanılan t-test sonuçları

\begin{tabular}{|c|c|c|c|c|}
\hline Gruplar & Seviyeler & Bölgeler & Ort \pm SS & $\mathbf{P}$ \\
\hline \multirow{6}{*}{$\begin{array}{l}\text { Grup } \\
1 \text { (One } \\
\text { Curve) }\end{array}$} & \multirow{2}{*}{$3 \mathrm{~mm}$} & B-L & $0,47 \pm 0,16$ & \multirow{2}{*}{0,930} \\
\hline & & M-D & $0,49 \pm 0,14$ & \\
\hline & \multirow{2}{*}{$6 \mathrm{~mm}$} & B-L & $0,43 \pm 0,13$ & \multirow{2}{*}{0,243} \\
\hline & & M-D & $0,20 \pm 0,12$ & \\
\hline & \multirow{2}{*}{$9 \mathrm{~mm}$} & B-L & $0,29 \pm 0,12$ & \multirow{2}{*}{0,379} \\
\hline & & M-D & $0,45 \pm 0,12$ & \\
\hline \multirow{6}{*}{$\begin{array}{c}\text { Grup 2 } \\
\text { (Hyflex) }\end{array}$} & \multirow{2}{*}{$3 \mathrm{~mm}$} & B-L & $0,40 \pm 0,25$ & \multirow{2}{*}{1} \\
\hline & & M-D & $0,40 \pm 0,25$ & \\
\hline & \multirow{2}{*}{$6 \mathrm{~mm}$} & B-L & $0,63 \pm 0,23$ & \multirow{2}{*}{0,427} \\
\hline & & M-D & $0,38 \pm 0,19$ & \\
\hline & \multirow{2}{*}{$9 \mathrm{~mm}$} & B-L & $0,37 \pm 0,10$ & \multirow{2}{*}{0,429} \\
\hline & & M-D & $0,58 \pm 0,24$ & \\
\hline \multirow{6}{*}{$\begin{array}{l}\text { Grup } 3 \\
\text { (WaveOne } \\
\text { GOLD) }\end{array}$} & \multirow{2}{*}{$3 \mathrm{~mm}$} & B-L & $0,51 \pm 0,18$ & \multirow{2}{*}{0,450} \\
\hline & & M-D & $0,30 \pm 0,20$ & \\
\hline & \multirow{2}{*}{$6 \mathrm{~mm}$} & B-L & $0,62 \pm 0,14$ & \multirow{2}{*}{0,461} \\
\hline & & M-D & $0,40 \pm 0,24$ & \\
\hline & \multirow{2}{*}{$9 \mathrm{~mm}$} & B-L & $0,25 \pm 0,19^{c}$ & \multirow[t]{2}{*}{$\mathbf{0 , 0 2 9}$} \\
\hline & & & $0,83 \pm 0,11^{£}$ & \\
\hline
\end{tabular}

Gruplarn her bir seviyedeki merkezleyebilme oranlarnın bölgesel (OrtıSS) olarak karșllaşturlmasımı vermektedir. *Sütun içinde üst simge ile gösterilen farklı karakterler bölgeler arası farklılı̆̆ı göstermektedir ( $\mathrm{p}<0,05)$. 


\section{Tartışma}

Kök kanalının mekanik preparasyonunun amacı orjinal kanal anatomisine bağlı kalarak kanal duvarlarının temizlenmesidir. Kök kanalının preparasyon aşamasında endodontik enstrümanların rijit yapısı nedeniyle kök kanalında transportasyon gerçekleşir. Bu kök kanalının ve enstrümanların temas noktalarında düzensiz stres dağılımlarına yol açabilir. Bu nedenle enstrümanlar kanaldaki şeklini geri kazanma eğilimindedir (14). Transportasyon kök kanalının fizyolojisindeki iatrojenik değişimdir. Kök kanalı transportasyonu çeşitli sorunlara ve hatalara neden olabilir. Apikal bölgenin yetersiz debridmanına ve kök kurvatürünün konkav yüzeyinin koronal bölgesinde aşırı dentin kaldırılmasına neden olabilir (15). Ayrıca apikal foramende zip oluşumuna veya perforasyona neden olabilir.

Kanal praparasyonunun değerlendirilmesinde rezin bloklar ve çekilmiş dişlerin kullanımı yaygındır. Rezin blokların kanal çapı, kök uzunluğu, kök kurvatür açılarının standart olması araştırma için standardizasyon sağlamasına karşın, mekanik özelliklerinin dentinden farklı olmaları ideal preparasyon analizi için problem oluşturmaktadır. Pulpa çevresindeki dentinin mikrosertliğinin rezin bloklardan yaklaşık iki kat fazla olması, kök kanal preparasyonu sırasında enstrümanlarda daha yüksek streslerin oluşmasına neden olur (16). Bu nedenlerden dolayı çalışmamızda çekilmiş insan dişleri kullanıldı.

Kök kanal preparasyonunun değerlendirilmesinde görüntü teknikleri klinik alanda kök kanal transportasyonunun değerlendirilmesinde daha güvenilir sonuçlar verebileceği bildirilmiştir (17). KIBT görüntülerinde doğrusal ölçümlerin doğruluğu ve tekrarlanabilirliği birçok araştırmada incelenmiş ve bu çalışmaların sonucunda doğrusal ölçüm yönteminin uygulanabilir bir analiz yöntemi olduğu sonucuna varılmıştır. KIBT görüntülerinde doğrusal ölçümlerde voksel boyutunun etkisinin araştırıldığı birçok çalışmada voksel boyutunun değişmesiyle doğrusal ölçümlerin etkilenmediği bildirilmiştir. $\mathrm{Bu}$ nedenle bu çalışmada $0.15 \mathrm{~mm} 3$ voksel boyutunda alınan görüntülerde analiz yapıldı.

Tek eğe sistemleri daha kısa preparasyon zamanı, daha az prosedür hatası ve daha kolay uygulama gibi avantajları ile dikkat çekmektedir. $\mathrm{Bu}$ nedenle çalışmamızda rotasyonel (One Curve, Hyflex EDM) ve resiprokal (WaveOne GOLD) hareket ile çalışan 3 yeni nesil tek eğe sistemi seçildi. Rotasyonel ve resiprokal hareketli döner enstrümanların kanal transportasyonlarına etkisi çeşitli çalışmalarda karşılaştırılmıştır. Birçok çalışma resiprokal hareketin kanal transportasyonunu önlemede daha etkili olduğunu rapor ederken, bazı çalışmalar da rotasyonel hareketin daha az kanal transportasyonuna neden olduğunu rapor etmişlerdir (18-21). $\mathrm{Bu}$ çalışmada $3 \mathrm{~mm}$ seviyede, bukko-lingual düzlemde One Curve eğe sistemi en az kanal transportasyonuna neden olan, Hyflex EDM eğe sistemi en fazla kanal transportasyonuna neden olan eğe sistemidir. Her iki eğe sistemi de rotasyonel hareketle çalışan eğe sistemleridir. $\mathrm{Bu}$ çalışmaya göre eğe sistemlerinin çalışma prensibi yönünden kanal transportasyonuna etkisi olmadığ 1 düşünülmektedir.

Eğe sistemlerinin merkezleyebilme oranları açısından karşılaştırıldığında tüm bölgelerde ve seviyelerde merkezleyebilme oranları açısından eğeler arasında herhangi bir fark bulunmamıştır. $\mathrm{Bu}$ durum eğelerin hareket yönlerinin merkezleyebilme oranlarına herhangi bir etkisini olmadığını göstermektedir. Literatürde daha önce yapılan çalışmalar incelendiğinde bizim sonuçlarımızla benzer sonuçlar bulunmaktadır $(17,20)$. Çapar ve ark. (22) farklı hareket yönünde çalışan 6 döner eğe sitemlerini karşılaştırdıkları çalışmada, eğe sitemlerinin transportasyon ve merkezleyebilme oranları arasında herhangi bir farklılık bulmamışlardır. Elsherief ve ark (23) KIBT kullanarak 3 farklı rotasyonel hareketle çalışan Ni-Ti eğenin kurvatürlü kanallarda toplam kök kanal transportasyon oranını değerlendirmişler ve her üç eğe sisteminin orijinal kök kanal kurvatürü ve formunu iyi koruduğunu ve eğeler arasında herhangi bir faklılık olmadığını bildirmişlerdir. Venino ve ark (24) Protaper Next ve Hyflex EDM eğelerinin kanal transportasyon oranları ve merkezleyebilme oranlarını karşılaştırdıkları çalışmada Hyflex EDM sisteminin daha az transportasyon daha fazla merkezleyebilme oranına sahip olduğu sonucuna ulaşmışlardır. Saber ve ark (25) yaptıkları bir başka çalışmada 2 farklı resiprokal hareket yapan tek eğe sistemi ile 1 rotasyonel hareket yapan tek eğe sisteminin apikal transportasyon oranlarının karşılaştırıldığ çalışmada resiprokal hareket yapan eğelerin daha az apikal transportasyona neden olduğunu bildirmişlerdir. Bizim çalışmamızda elde ettiğimiz bulguya göre, apikale en yakın $3 \mathrm{~mm}$ seviyesindeki kanal transportasyon oran1 0,004$0,26 \mathrm{~mm}$ arasında değişmekte olup, bu değer Wu ve ark (25) tanımladığı kritik kanal transportasyon değerinden az olduğu görülmektedir.

$\mathrm{Bu}$ çalışmanın avantajı, değerlendirmede 3 boyutlu görüntüleme sağlayan KIBT görüntülerinin kullanılmasıdır. Ancak çalışmanın in-vitro olarak planlanması dezavantajını oluşturmaktadır. Klinik koşullarda, farklı uygulama yöntemleri kullanılarak farklı eğe sistemleri ile daha fazla çalışma yapılmasına ihtiyaç duyulmaktadır.

\section{Sonuç}

$\mathrm{Bu}$ çalışmanın limitasyonları dahilinde WaveOne GOLD, Hyflex EDM ve One Curve eğe sistemlerinin orijinal kök kanal formunu koruduğu gözlemlendi. Eğe sistemlerinin çalışma prensibinin transportasyon ve merkezleyebilme oranlarına etkisinin olmadığı gözlemlendi. One Curve eğe sistemi apikal bölgede bukkolingual düzlemde en az kök kanal transportasyonuna neden olan eğe sistemidir. Ayrıca her üç eğe sisteminin merkezleyebilme oranlarının benzer olduğu gözlendi.

\section{Teşekkür}

Çalışmamızın istatistiksel analizler konusunda yardımcı olan Prof. Dr. Hikmet ORHAN' a katkılarından dolayı teşekkür ederiz.

\section{Kaynaklar}

1. Elnaghy AM, Elsaka SE. Evaluation of root canal transportation, centering ratio, and remaining dentin thickness associated with ProTaper Next instruments with and without 
glide path. J Endod 2014; 40(12): 2053-6.

2. Shah DY, Wadekar SI, Dadpe AM, Jadhav GR, Choudhary LJ, Kalra DD. Canal transportation and centering ability of protaper and self-adjusting file system in long oval canals: An ex-vivo cone-beam computed tomography analysis. J Conserv Dent 2017; 20(2): 105.

3. Mittal A, Dadu S, Singh NS, Singh S, Gupta B, Abraham A, et al. Comparative Assessment of Canal Transportation and Centering Ability of Reciproc and One Shape File Systems Using CBCT-An In Vitro Study.J Clin Diagn Res 2017; 11(4): 31.

4. Micro Mega. One Curve. Available at: https://micro-mega. com/wp-content/uploads/2018/03/Brochure-One-CurveEN-1.pdf

5. Coltene.HyflexEDM..Available.at: : https://www.coltene. com/fileadmin/Data/EN/

Products/Endodontics/Root_Canal_Shaping/HyFlex_ EDM/31328A_HyFlexEDM_Bro

chure_US.pd

6. Dentsply Tulsa Dental Specialties. Wave One Gold. Available at: https:/www.dentsply.com/content/dam/ dentsply/pim/manufacturer/Endodontics/Obturation/GuttaPercha-Points/WaveOne-Gold-Gutta-Percha-Points/W1GBrochure-EN.pdf.

7. Hashem AAR, Ghoneim AG, Lutfy RA, Foda MY, Omar GAF. Geometric analysis of root canals prepared by four rotary NiTi shaping systems. J Endod 2012; 38(7): 996-1000.

8. Bernardes RA, Rocha EA, Duarte MAH, Vivan RR, de Moraes IG, Bramante AS, et al. Root canal area increase promoted by the EndoSequence and ProTaper systems: comparison by computed tomography. J Endod 2010; 36(7): 1179-82.

9. Pasternak-Júnior B, Sousa-Neto M, Silva R. Canal transportation and centring ability of RaCe rotary instruments. Int Endod J 2009; 42(6): 499-506.

10. Marzouk AM, Ghoneim AG. Computed tomographic evaluation of canal shape instrumented by different kinematics rotary nickel-titanium systems. J Endod 2013; 39(7): 906-9.

11. da Silva NC, Barriviera M, Junqueira JLC, Panzarella FK, Raitz R. Intraobserver and interobserver reproducibility in linear measurements on axial images obtained by cone-beam computed tomography. Imaging Sci Dent 2017; 47(1): 11-5.

12. Kamburoğlu K, Kolsuz E, Kurt H, Kılıç C, Özen T, Paksoy CS. Accuracy of CBCT measurements of a human skull. J Digit Imaging 2011; 24(5): 787-93.

13. Moshfeghi M, Tavakoli MA, Hosseini ET, Hosseini AT, Hosseini IT. Analysis of linear measurement accuracy obtained by cone beam computed tomography (CBCT-
NewTom VG). Dent Res J 2012; 9(1): 57.

14. Javaheri HH, Javaheri GH. A comparison of three Ni-Ti rotary instruments in apical transportation. J Endod 2007; 33(3): 284-6.

15. Peters OA. Current challenges and concepts in the preparation of root canal systems: a review. J Endod 2004; 30(8): 559-67.

16. Khalilak Z, Fallahdoost A, Dadresanfar B, Rezvani G. Comparison of extracted teeth and simulated resin blocks on apical canal transportation. Iran Endod J 2008; 3(4): 109.

17. Hülsmann M, Peters OA, Dummer PM. Mechanical preparation of root canals: shaping goals, techniques and means.Endod Topics 2005; 10(1): 30-76.

18. Maia Filho M, de Castro Rizzi C, Bandeca Coelho M, Freitas Santos S, Mayanne Oliveira Costa L, Nunes Carvalho $\mathrm{C}$, et al. Shaping ability of reciproc, unicone, and protaper universal in simulated root canals. ScientificWorldJournal 2015: 2015.

19. Tambe VH, Nagmode PS, Abraham S, Patait M, Lahoti PV, Jaju N. Comparison of canal transportation and centering ability of rotary protaper, one shape system and wave one system using cone beam computed tomography: an in vitro study. J Conserv Dent 2014; 17(6): 561.

20. Dhingra A, Ruhal N, Miglani A. Evaluation of single file systems Reciproc, Oneshape, and WaveOne using cone beam computed tomography-an in vitro study.J Clin Diagn Res 2015; 9(4): ZC30.

21. Saber S, Nagy M, Schäfer E. Comparative evaluation of the shaping ability of $\mathrm{W}$ ave $\mathrm{O}$ ne, $\mathrm{R}$ eciproc and $\mathrm{O}$ ne $\mathrm{S}$ hape single-file systems in severely curved root canals of extracted teeth. Int Endod J 2015; 48(1): 109-14.

22. Capar ID, Ertas H, Ok E, Arslan H, Ertas ET. Comparative study of different novel nickel-titanium rotary systems for root canal preparation in severely curved root canals.J Endod. 2014; 40(6): 852-6.

23. Elsherief SM, Zayet MK, Hamouda IM. Cone-beam computed tomography analysis of curved root canals after mechanical preparation with three nickel-titanium rotary instruments. J Biomed Res 2013; 27(4): 326.

24. Venino PM, Citterio CL, Pellegatta A, Ciccarelli M, Maddalone M. A Micro-computed Tomography Evaluation of the Shaping Ability of Two Nickel-titanium Instruments, HyFlex EDM and ProTaper Next. J Endod 2017; 43(4): 62832.

25. Wu M-K, Fan B, Wesselink PR. Leakage along apical root fillings in curved root canals. Part I: effects of apical transportation on seal of root fillings. J Endod 2000; 26(4): 210-6. 